The Open Automation and Control
Systems Journal
CrossMark
Content list available at: www.benthamopen.com/TOAUTOCJ/
DOI: $10.2174 / 1874444301608010001$

\title{
Retraction Notice: CS-1-SVM: Improved One-class SVM for Detecting API Abuse on Open Network Service
}

\author{
Chen Hai-ting* \\ College of Network Communication, Zhejiang Yuexiu University of Foreign Languages, Shaoxin, China
}

\section{RETRACTION}

The Publisher and Editor have retracted this article [1] in accordance with good ethical practices. It was found plagiarised and similar article was published in other journal [2]. The article was published on-line on 14-09-2015.

\section{REFERENCES}

[1] Hai-ting C. CS-1-SVM: Improved one-class SVM for detecting API abuse on open network service. Open Autom Control Syst J 2015; 7 : 1293-300.

[1] Xie M, Huang W, Yang L, Yang Y. CS-1-SVM: Improved one-class SVM for detecting API abuse on open network service. J Comput Theor Nanosci 2015; 12: 4068-75.

\section{(c) Chen Hai-ting; Licensee Bentham Open.}

This is an open access article licensed under the terms of the Creative Commons Attribution-Non-Commercial 4.0 International Public License (CC BY-NC 4.0) (https://creativecommons.org/licenses/by-nc/4.0/legalcode), which permits unrestricted, non-commercial use, distribution and reproduction in any medium, provided the work is properly cited.

\footnotetext{
* Address correspondence to this author at the College of Network Communication, Zhejiang Yuexiu University of Foreign Languages, Shaoxin, China; Tel: +8615957572387; E-mail: chenht80@163.com
} 